\title{
Bladder wall biomechanics: A comprehensive study on fresh porcine urinary bladder
}

Sami Jokandan, Maryam; Ajalloueian, Fatemeh; Edinger, Magnus; Stubbe, Peter Reimer; Baldursdottir, Stefania; Chronakis, loannis S.

Published in:

Journal of the Mechanical Behavior of Biomedical Materials

Link to article, DOI:

10.1016/j.jmbbm.2017.11.034

Publication date:

2018

Document Version

Peer reviewed version

Link back to DTU Orbit

Citation (APA):

Sami Jokandan, M., Ajalloueian, F., Edinger, M., Stubbe, P. R., Baldursdottir, S., \& Chronakis, I. S. (2018).

Bladder wall biomechanics: A comprehensive study on fresh porcine urinary bladder. Journal of the Mechanical Behavior of Biomedical Materials, 79, 92-103. https://doi.org/10.1016/j.jmbbm.2017.11.034

\section{General rights}

Copyright and moral rights for the publications made accessible in the public portal are retained by the authors and/or other copyright owners and it is a condition of accessing publications that users recognise and abide by the legal requirements associated with these rights.

- Users may download and print one copy of any publication from the public portal for the purpose of private study or research.

- You may not further distribute the material or use it for any profit-making activity or commercial gain

- You may freely distribute the URL identifying the publication in the public portal 


\section{Author's Accepted Manuscript}

Bladder wall biomechanics: A comprehensive study on fresh porcine urinary bladder

Maryam Sami Jokandan, Fatemeh Ajalloueian, Magnus Edinger, Peter Reimer Stubbe, Stefania Baldursdottir, Ioannis S. Chronakis

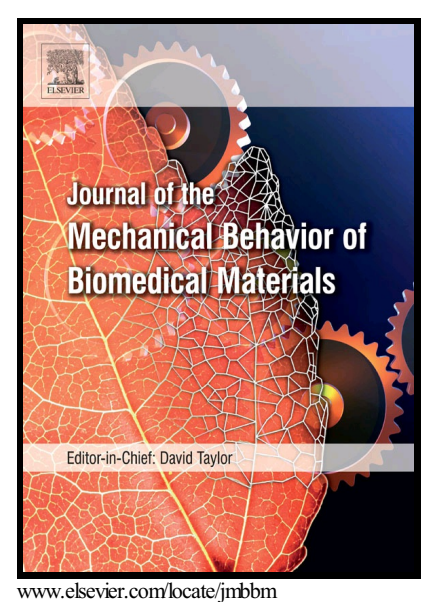

PII: $\quad$ S1751-6161(17)30522-2

DOI: $\quad$ https://doi.org/10.1016/j.jmbbm.2017.11.034

Reference: JMBBM2591

To appear in: Journal of the Mechanical Behavior of Biomedical Materials

Received date: 18 July 2017

Revised date: 15 November 2017

Accepted date: 21 November 2017

Cite this article as: Maryam Sami Jokandan, Fatemeh Ajalloueian, Magnus Edinger, Peter Reimer Stubbe, Stefania Baldursdottir and Ioannis S. Chronakis, Bladder wall biomechanics: A comprehensive study on fresh porcine urinary bladder, Journal of the Mechanical Behavior of Biomedical Materials, https://doi.org/10.1016/j.jmbbm.2017.11.034

This is a PDF file of an unedited manuscript that has been accepted for publication. As a service to our customers we are providing this early version of the manuscript. The manuscript will undergo copyediting, typesetting, and review of the resulting galley proof before it is published in its final citable form. Please note that during the production process errors may be discovered which could affect the content, and all legal disclaimers that apply to the journal pertain. 
Bladder wall biomechanics: A comprehensive study on fresh porcine urinary bladder

Maryam Sami Jokandan ${ }^{1 \#}$, Fatemeh Ajalloueian*1\#, Magnus Edinger ${ }^{2}$, Peter Reimer Stubbe ${ }^{3}$, Stefania Baldursdottir ${ }^{2}$, and Ioannis S. Chronakis ${ }^{1}$

1. Research Group for Nano-Bio Science, National Food Institute, Technical University of Denmark, Kemitorvet, 2800 Kgs. Lyngby, Denmark

2. Department of Pharmacy, University of Copenhagen, Universitetsparken 2, 2100 Copenhagen, Denmark

3. Research Group for Food Production Engineering, National Food Institute, Technical University of Denmark, Søltofts Plads, 2800, Kgs. Lyngby, Denmark

*Corresponding author email: faaj@food.dtu.dk

\# equally contributed to this work. 


\section{Highlights:}

- A comprehensive mechanical evaluation of fresh porcine bladder wall is performed.

- Outcomes from current study provide researchers with a data-base to refer to.

- Ball-burst was found as an easy and reliable test method to study the BW in whole.

- Commenting upon isotropy/anisotropy of bladder wall needs to be subjective.

- BW behaves isotropic under physiologic conditions and at low strain loads. 


\section{ACCEPTED MANUSCRIPT}

\section{Abstract}

Regenerative medicine for reconstructive urogenital surgery has been widely studied during the last two decades. One of the key factors affecting the quality of bladder regeneration is the mechanical properties of the bladder scaffold. Insight into the biomechanics of this organ is expected to assist researchers with functional regeneration of the bladder wall. Due to extensive similarities between human bladder and porcine bladder, and with regard to lack of comprehensive biomechanical data from the porcine bladder wall (BW), our main goal here was to provide a thorough evaluation on viscoelastic properties of fresh porcine urinary BW. Three testing modes including Uniaxial tensile, Ball-burst (BB) and Dynamic Mechanical Analyses (DMA) were applied in parallel. Uniaxial tests were applied to study how different circumferential and longitudinal cut-outs of lateral region of BW behave under load. DMA was used to measure the viscoelastic properties of the bladder tissue (storage and loss modulus) tested in a frequency range of 0.1 to $3 \mathrm{~Hz}$. $\mathrm{BB}$ was selected as a different technique replicating normal physiological conditions where the BW is studied in whole. According to uniaxial tests, the anisotropic behavior of bladder was evident at strain loads higher than $200 \%$. According to DMA, storage modulus was found to be consistently higher than loss modulus in both directions, revealing the elasticity of the BW. The stress-strain curves of both uniaxial and BB tests showed similar trends. However, the ultimate stress measured from BB was found to be around 5 times of the relevant stress from uniaxial loading. The ultimate strain in BB $(389.9 \pm 59.8)$ was interestingly an approximate average of longitudinal (358 \pm 21$)$ and circumferential $(435 \pm 69)$ rupture strains. Considering that each testing mode applied here reveals distinct information, outcomes from the combination of the three can be considered as a helpful data-base to refer to for researchers aiming to regenerate the bladder.

Keywords: Biomechanics, Urinary bladder wall, Uniaxial tensile, Ball-burst, DMA, Viscoelastic 


\section{ACCEPTED MANUSCRIPT}

\section{Introduction}

Urinary bladder (UB) is a hollow organ which stores urine (up to $400 \mathrm{ml})^{1}$ at low-pressure in a continent reservoir and expels the stored urine in an efficient, timely and coordinated manner. UB is able to keep pressure nearly constant due to the stress relaxation property of bladder wall. At normal voiding condition, the bladder empties quickly and completely by an initial voluntary reduction in intra-urethral pressure (i.e., urethral relaxation) followed by a continuous detrusor contraction that leads to complete bladder emptying within a normal time-span ${ }^{2}$.

Debilitating incontinence affects both men and women (200 million worldwide $)^{3}$ which expand from overactive bladder, to urinary incontinence, bladder obstruction and cancer. Today the treatment procedure for voiding dysfunction is use of bowel tissue parts to divert urine. ${ }^{4}$ However use of bowel for this purpose is not optimal due to its long-term complications coupled with high adsorption, permeability and excess mucus production ${ }^{5-7}$. Hence, attentions are brought towards development of biomaterials for bladder repair/replacement.

Research in bladder biomechanics will not only benefit tissue engineering of bladder, but also help provide a more thorough understanding of normal bladder function and how it alters by diseases and treatments. Substantially, there has been extensive research on bladder's mechanical properties and scientists have developed mathematical models to describe them. Some studies are based on urodynamic investigations of intact animal and human bladders ${ }^{8-10}$, which provide us with valuable information about bladders biomechanics. However, they evaluate the organ in whole and cannot isolate the effect of non-uniform wall stress distribution ${ }^{11}$, bladder wall thickness, structural changes in the detrusor and surrounding tissues, neural activities ${ }^{12}$ and external loading by pelvic organs.

There are extensive research on isolated bladder tissue parts as well ${ }^{13,14,15}$. But there are challenges in comparing data across literature due to several variables such as test speed, load history, 
environmental conditions (e.g. temperature and humidity), sample preparation, preservation and properties e.g. species, age, sex.

Reconstruction of bladder has been an aspiration for urologists over a century ${ }^{16-19}$. To this end, they have faced several challenges, including fabricating an ideal biomaterial with mechanical properties comparable to those of biological bladder. The mechanical properties of the biomaterials are essential in their successful remodeling, and overall clinical stability. Ideally, biomaterials intended for tissue replacement should exhibit mechanical properties that match those of the tissue. In this regard, an understanding of the bladder biomechanics is essential. The published studies regarding the mechanical properties of UB are not sufficient to quantify stress-strain-time relationships governing the three-dimensional bladder deformation. It is arguable to compare results from different testing techniques across literature as the test modes and analysis methods are inherently different. Lack of complete data on bladder biomechanics is one of the main obstacles in the field of bladder tissue engineering. In this study we have performed a comprehensive study on mechanical properties of fresh porcine UB. The constitutive behaviors of bladder wall tissue such as the stressstrain relationship, isotropic/anisotropic behavior, stress relaxation, tangential stiffening and frequency dependency of bladder wall tissue are fairly well described by the proposed study. In order to properly asses that, three different testing modes of uniaxial tensile, ball-burst, and Dynamic mechanical analysis have been applied.

\section{Materials and methods}

\subsection{Sample preparation}

Porcine bladders from female sex were obtained from an abattoir (Kosakgården - Denmark) within one hour of slaughtering the animals. Connective tissue and adipose tissue were removed from the outer surface of the bladders. Bladders were dissected along the superior-to-anterior direction 


\section{ACCEPTED MANUSCRIPT}

(Figure 1) and cleaned from urine with deionized (DI) water. Practically it is not possible to control simultaneously spiking and contractile activity of smooth muscle in vitro but in order to maintain normal, basal muscle tone, each bladder was immersed in Krebs solution in presence of calcium, and was stored in room temperature until experiment was performed. Krebs solution contains $113 \mathrm{mM} \mathrm{NaCl}, 4.7 \mathrm{mM} \mathrm{KCl}, 1.2 \mathrm{mM} \mathrm{MgO}_{4}, 25 \mathrm{mM} \mathrm{NaHCO}_{3}, 1.2 \mathrm{mM} \mathrm{KH}_{2} \mathrm{PO}_{4}, 5.9 \mathrm{mM}$ dextrose, and $3.3 \mathrm{mM} \mathrm{CaCl}_{2}$. All the experiments were performed in less than 12 hours from slaughter of animals (storage time was $<10$ hours for most samples). Considering that Bladder's mechanical properties change at different regions ${ }^{11}$, the region of interest in this study was fixed to the middle part of the bladder as marked in the Figure 1. In order to keep the specimens hydrated during experiments, a fine mist of Krebs solution was applied to the tissue at frequent intervals of one minute. All measurements were conducted under ambient temperature $\left(25 \pm 2{ }^{\circ} \mathrm{C}\right)$.

\subsection{Experimental methods}

\subsubsection{Thickness measurements}

In order to calculate wall stress from raw data, the thickness of test specimens were measured using Texture Analyzer (TA.XT plus) equipped with the stock software plus a macro and a metal cylindrical probe (diameter of $10 \mathrm{~mm}$ ). The specimens were flattened out on the metal plate, and the probe was lowered down to the upper side (surface) of the bladder at strain rate of $5 \mathrm{~mm} / \mathrm{min}$ until a force of $2 \mathrm{~g}$ was sensed by the probe. The height of the probe was reported by the built-in software. The thickness of the bladder was measured at 5 different points and an average was taken.

\subsubsection{Preconditioning}

Preconditioning of biological soft tissue is considered as an essential step towards establishing a repeatable set of experiments ${ }^{20,21}$. In this study, all specimens were preconditioned prior to the 


\section{ACCEPTED MANUSCRIPT}

actual tests. Preconditioning was performed by repeatedly loading and unloading (cyclic) the specimens at strain rate of $10 \mathrm{~mm} / \mathrm{min}$. The strain load used for preconditioning the specimens, was set to be the same as the strain load used in the actual tests. The different strain amplitudes used in this study for uniaxial and BB tests are $2.5 \%, 5 \%, 10 \%, 20 \%, 50 \%, 100 \%, 200 \%$ and $300 \%$. Loading and unloading under the constant strain rate of $10 \mathrm{~mm} / \mathrm{min}$ was repeated until the stressstrain loop of samples appeared to be stable and replicable. The recovery time between each cycle was fixed to 30 seconds. In order to avoid the effect of loading history variable on the experiments, all specimens were preconditioned at a fixed number of cycles and for every new experiment at a different strain, a new sample was employed.

\subsection{Uniaxial tensile test}

For uniaxial tensile tests, all samples were cut into $1 \mathrm{~cm} \times 6 \mathrm{~cm}$ rectangles in both longitudinal (superior-to-anterior) and circumferential directions using a surgical scalpel. Specimens were mounted on the mechanical testing machine Texture Analyzer (TA.XT plus) by means of Tensile Grip-Titanium (Figure 2). The distance between the grips was calibrated to $4 \mathrm{~cm}$ and $1 \mathrm{~cm}$ at each end of the test specimens were secured into the tensile grip.

In uniaxial tensile tests, $0.05 \mathrm{~N}$ force was applied as a reference point for zero-displacement. In each test, load and displacement data were acquired and converted to stress $(\sigma)$ and strain $(\varepsilon)$ using the initial cross section area (engineering stress) and initial height of the specimens.

Three types of tests were performed during the uniaxial tensile test; (1) load/unload test, (2) monotonic test and (3) rupture test. During load/unload test, the specimens were loaded to the desired strain at $10 \mathrm{~mm} / \mathrm{min}$ followed by unloading at the same rate. Such a low strain rate seems to be a close replication to physiological filling in bladder wall, and has been used in other studies as the most optimal rate for testing bladder specimens. ${ }^{11}$ Tensile stress, stiffness and hysteresis were 


\section{ACCEPTED MANUSCRIPT}

calculated from these tests. During monotonic tests, specimens were ramped up to the designated strain amplitude at speed of $60 \mathrm{~mm} / \mathrm{min}$ and kept there for 30 minutes. Then the stress-strain behavior and stress-relaxation behavior of the specimens were studied. In rupture test, samples were loaded at $10 \mathrm{~mm} / \mathrm{min}$ until break, and ultimate stress and strain were registered (Figure 2 (c)). The raw data were analyzed using the Stable Micro Systems Exponent v6.1.10 software. Different strain amplitudes of $2.5 \%$ to $300 \%$ were applied for uniaxial and BB tests. The minimum number of samples used for each specific test was 5 samples.

\subsection{Ball-burst testing}

For BB tests, the opened bladder specimen was mounted on a homemade setup, which was built for fixing the specimen during experiments. The setup included a stainless-steel cylinder with a circular aperture of diameter $48 \mathrm{~mm}$ on the top (Figure 3). An indentation was assigned around the circular aperture to prevent slippage during test. The bladder was fixed with the mid-portion (middle region - Figure 1) centered directly over the circular aperture using pull-tight straps. The texture analyzer machine was equipped with a $\mathrm{BB}$ compression tool in which a $25 \mathrm{~mm}$ polypropylene sphere was advanced through the aperture in a perpendicular direction to the test specimen (see Figure 3 ). The reference point was fixed to $0.05 \mathrm{~N}$ force during $\mathrm{BB}$ tests.

Two testing types were performed (1) load/unload test and (2) rupture test as described earlier. Briefly for load/unload test, the ball was lowered against the specimen on the aperture at a constant strain rate of $10 \mathrm{~mm} / \mathrm{min}$ to the designate strain followed by unloading at the same rate. In rupture test, the samples were tested to rupture by advancing the polypropylene ball at a rate of $10 \mathrm{~mm} / \mathrm{min}$ through the aperture. The failure stress was defined as the maximum stress prior to rupture of the specimen. Every sample was preconditioned prior to the actual tests as described elsewhere in this article. The TA machine recorded force $(\mathrm{N})$ and displacement $(\mathrm{mm})$ data of the ball. The raw data 


\section{ACCEPTED MANUSCRIPT}

were used to determine stress and strain using an analytical method as described in the following section. The resulting data were analyzed using Stable Micro Systems Exponent v6.1.10 software.

\subsection{DMA}

Dynamic mechanical analysis was conducted on a TA instrument Q-800 DMA controlled by TA instrument Advantage software v 5.5.22 (TA Instruments, New Castle, DE, USA). The samples were cut into pieces with an approximate length of $40 \mathrm{~mm}$ and width of $6 \mathrm{~mm}$ using a surgical scalpel. The sample sizes were measured before analysis using a caliper (Mitutoyo Corporation, Kawasaki, Japan) and were mounted on the DMA at an approximate length of $20 \mathrm{~mm}$. A preload force of $0.01 \mathrm{~N}$ was applied and the stretched length of the sample was measured by the software. The samples were subjected to a frequency sweep from 0.1 to $3 \mathrm{~Hz}$, measuring 5 data points per decade. The oscillation amplitude was $200 \mu \mathrm{m}$, corresponding to approximately $1 \%$ of the sample length. The samples were measured both in the circumferential and longitudinal directions and the storage and loss moduli were recorded ( $\mathrm{n}=4$ for each sample direction). In order to avoid the samples drying out, they were sprayed with buffer every minute. The resulting data were analyzed using TA Instruments Universal Analysis 2000 v4.5 software (TA Instruments).

In dynamic mechanical analysis, a sample is mounted between two clamps and subjected to a sinusoidal movement. The frequency of the movement and the displacement can be varied in order to obtain the mechanical properties of materials at different settings. In DMA, the sinusoidal movement, called the stress $(\sigma)$, is applied to the material and the resulting strain $(\varepsilon)$ is measured. For a fully elastic solid, the strain and stress will be in phase, while for a fully viscous fluid, there will be a 90 degree phase lag. Mathematically they can be described according to Eqn. 1 and Eqn. 2 .

$\sigma=\sigma_{0} \cdot \sin (t \cdot \omega+\delta)$

Eqn. 1

$\varepsilon=\varepsilon_{0} \cdot \sin (t \cdot \omega)$

Eqn. 2 
Where $\omega$ is the frequency of the strain oscillation, $\mathrm{t}$ is time and $\delta$ is phase lag between stress and strain. From the stress and strain, the storage and loss moduli can be calculated. They are dependent on the sample dimensions and are calculated from the cross-sectional area of the samples. The storage modulus represents the stored energy, i.e. the elastic property of the sample, while the loss modulus represents the dissipated energy of the sample, i.e. the viscous property. The instrument used in this study measures the Force (F), the amplitude of deformation of the samples (A) and the phase angle $(\delta)$. From this the dynamic stiffness $\left(\mathrm{k}^{*}\right)$ is calculated as F/A. The storage and loss moduli are then calculated by multiplying the storage $\left(\mathrm{k}^{\prime}=\mathrm{k}^{*} \cdot \cos (\delta)\right)$ and loss stiffness $\left(\mathrm{k}^{\prime \prime}=\mathrm{k}^{*}\right.$. $\sin (\delta))$ with the geometry factor of the clamp used, which is L/As where $\mathrm{L}$ is sample length and As is the cross-sectional area. The storage and loss moduli are therefore calculated as Eqn. 3 and Eqn 4.

Storage modulus: $E^{\prime}=\left(\frac{F}{A}\right) \cdot \cos (\delta) \cdot\left(\frac{L}{A_{S}}\right)$

Eqn. 3

Loss modulus: $E^{\prime \prime}=\left(\frac{F}{A}\right) \cdot \sin (\delta) \cdot\left(\frac{L}{A_{s}}\right)$

Eqn. 4

The ratio between the loss and storage moduli is calculated as the tangent to the phase angle $(\tan (\delta))$ and describes the ratio of the elastic to the viscous properties in the sample.

\subsection{Analytically derived mechanical properties}

In order to describe the intrinsic properties of bladder wall, raw data were converted to stress and strain in all testing modes. In DMA and uniaxial test, force $(F)$ was converted to stress $(\sigma)$ by dividing it with the unloaded cross-sectional area (engineering stress), and displacement $(\Delta \mathrm{L})$ was converted to percentage strain $(\varepsilon)$ by dividing it with the initial length of specimen and was reported in percent. In this study ultimate stress is the stress that sample is exposed to prior to failure and ultimate strain is the deformation that the material can undergo prior to failure. Tangential stiffness is materials resistance to elastic deformation and is calculated from the slope of the initial part of the stress-strain curve. The hysteresis is calculated as the percentage of the loading work which is lost in a loading-unloading cycle Integrating relevant stress-strain curve yields the work per volume 
needed to deform the sample. The stress-strain curve for unloading is usually somewhat lower than for loading, indicating an energy loss due to internal friction in the sample material.For comparing the hysteresis value between different graphs, we calculated the hysteresis as the dissipated energy per cycle of loading and loading (the area between stress-strain loading-unloading curves) divided by the strain energy of loading.

Therefore, hysteresis is calculated using the following expression:

$$
\text { Hysteresis }=\frac{\int_{0}^{\varepsilon_{0}} \sigma_{\text {loading }}-\sigma_{\text {unloading }} d \varepsilon}{\int_{0}^{\varepsilon_{0}} \sigma_{\text {loading }} d \varepsilon} \cdot 100
$$

where $\varepsilon$ is the sample deformation. The hysteresis takes values from 0 to $100 \%$.

For calculating stress and strain from BB raw data, the following analytical solutions were developed which were inspired from a study by Badylak and his group ${ }^{15}$. For simplicity, calculations are based on the position of the polypropylene ball after traveling at least $12.5 \mathrm{~mm}$ into the bladder (Figure 4). For this analytical solution, the following assumptions were made:

(a) Bladder wall is isotropic with fiber orientations uniformly distributed

(b) Bladder wall is incompressible

(c) There is negligible shear stress and friction between the ball and the specimen

(d) The stress distribution throughout the bladder wall is homogeneous

Bladder wall stress was calculated using equation 6 which is slightly different from the equation proposed in the article by Badylak et al. For more detailed statement and complete derivation, please refer to their article ${ }^{15}$.

$\sigma=F / \pi \sin ^{2} \varphi\left(h^{2}+2 d \cdot h\right)$

6) 
in which $\mathrm{F}$ is force applied to the polypropylene ball by the bladder, $\mathrm{d}$ is the radius of the polypropylene ball, $\mathrm{h}$ is the bladder thickness which is calculated in an iterative fashion using bisections method and $\varphi$ is the contact angle (Figure 4) and is calculated as follow:

$\varphi=\pi-\left(\left(\frac{\pi}{2}\right)-\tan ^{-1}\left(\frac{d}{f}\right)\right)-\left(\tan ^{-1} \frac{a}{b}\right)$

here $f$ is tangential length from the polypropylene ball clamp (Figure 4) and is calculated by:

$f=\sqrt{b^{2}+a^{2}-d^{2}}$

where $a$ is the distance between the central axis of the polypropylene ball and the BB cage clamp and $\mathrm{b}$ is the distance minus the ball's radius (Figure 4$)$. The average strain $(\lambda)$ was calculated by dividing the deformed length of the material by the original length:

$\lambda=\frac{d \cdot \varphi+f-a}{a} .100$

In this study a macro was written within the Exponent program and applied where these analytical methods were employed.

\subsection{Statistical analysis}

Graphpad Prism 6 (Graphpad software, CA, USA) was used to do statistical analyses. All data were expressed as mean \pm standard deviation of the sample mean. Comparisons between samples were made using unpaired t-Test. Differences were considered statistically significant when $\mathrm{p}<0.05$.

The sample size in each testing procedure was 5 .

\section{Results and Discussions}

Recent studies have addressed the importance of mechanical properties of the scaffolds developed for tissue engineering of $\mathrm{UB}^{22-24}$. It is however challenging to compare data from different studies 


\section{ACCEPTED MANUSCRIPT}

due to various variables. Such variables include sample preparation and preservation, testing environment and testing techniques. Each testing technique reveals distinct mechanical properties of UB and it is therefore challenging to compare data from different testing techniques across literature. In this study, we have used fresh porcine bladders of the same sex (female), and relatively the same age and weight. The porcine tissue was selected due to its extensive similarities to human bladder. Previous studies by Dahms et al. ${ }^{11}$ and Korossis et al. ${ }^{11}$ suggest that porcine bladder has extensive similarities to human bladder in histomorphometric conformation and mechanical behavior. In most studies, test samples were preserved at $-20^{\circ} \mathrm{C}$ prior to testing. Considering that the effect of storage temperature on bladder's mechanical properties is not systematically investigated yet $^{25}$, we applied fresh samples for all the experiments we performed in this study.

UB is understood to have anisotropic mechanical properties. In order to properly study the anisotropic properties of UB, uniaxial tensile test is performed in both circumferential and longitudinal directions. For understanding the multiaxial properties of UB, BB test is performed. This is a valuable testing technique for studying the biomechanics of bladder, since native bladder is exposed to multiaxial forces during filling and voiding. Dynamic mechanical analysis (DMA) also reveals mechanical properties of UB when it is exposed to frequency sweep. This was the first study, to the knowledge of the authors, which used three different testing techniques together to comprehensively investigate the biomechanics of fresh porcine bladders.

\subsection{Preconditioning}

Preconditioning is a helpful step to establishing a repeatable set of experiments. The structural composition of bladder wall, like any other soft tissue, allows it to adapt to loading gradually and showing a more consistent mechanical data. The importance of preconditioning has earlier been studied in various soft tissues ${ }^{20,21,26}$. Figure 5 illustrates stress-strain graph of porcine bladder during preconditioning in uniaxial tensile test. The test sample was in longitudinal direction and 


\section{ACCEPTED MANUSCRIPT}

was loaded cyclically up to $50 \%$ strain. The peak stresses and area bounded between load and unload curves (hysteresis) decreased with increasing the number of cycles until it reached a steady state with replicable loops. The hysteresis exhibited between loading-unloading stress-strain curves under cyclic loading is a representative of viscoelastic mechanical behavior of bladder wall tissue ${ }^{27}$. The curve in Figure 5 demonstrates repeatability from $9^{\text {th }}$ cycle. During the preconditioning cycles, the shape of stress-strain loops changed gradually until it reached a steady state with similar loops. The energy dissipated in the first loop was found to be higher than the last loop when the sample was fully preconditioned. Moreover, consecutive loading during preconditioning showed that the stress falls as the number of cycles increases. In other words, softening happens by preconditioning. Softening continues until the sample is preconditioned, where the stress no longer falls. It was also observed that the elastic part pervades over the viscous contribution by preconditioning. Regardless of load, 10 cycles was found (similar to the outcomes from the study of Korossis et $\mathrm{al}^{11}$ ) to be sufficient to produce a steady-state load-elongation response from all samples. Hence, all samples were preconditioned with 10 cycles in this study. As both circumferential and longitudinal specimens behaved identical during preconditioning, they were preconditioned with the same number of cycles.

\subsection{Uniaxial tensile test}

\section{Cyclic loading-unloading and Rupture}

Uniaxial test will provide us with valuable information about tension strength in bladder wall and its anisotropic properties. Fibers in bladder wall tend to have preferred directions ${ }^{11,28}$ which is supposed to give the bladder anisotropic property. In this study, this property was investigated using uniaxial tensile test in both circumferential (transversal) and longitudinal (superior-to-anterior) directions. Bladder tissue response to both monotonic and cyclic loading was analyzed, aiming to establish a relationship between these behaviors and to assess whether they are both affected by 


\section{ACCEPTED MANUSCRIPT}

material anisotropy. The results from the uniaxial tensile test at different strain amplitudes are summarized in Figure 6. It is worth mentioning that the average thickness of all applied bladders was measured to $5.66 \pm 1.2 \mathrm{~mm}$. A representative stress-strain plot for circumferential samples loaded to different strains from $2.5 \%$ to $300 \%$ strain is shown in Figure 6(a). The inset shows magnification of the graph for strain loads of less than 20\%. All samples exhibited the classic soft biological tissue stress-strain response comprising of an initial linear region (elastic phase) followed by a non-linear region before rupture ${ }^{29}$. Moreover, the slope of the graph changed slightly at low strain loads and increased exponentially at higher strain loads. This change is especially visible for strain amplitudes above $200 \%$. This can be explained by the wavy and crimped conformation of different fibers such as collagen fibers in bladder wall (Figure 6(b)). Bladder wall is composed of complex fiber reinforced structures. Under relaxed condition, the collagen fibers are woven into rhombic shaped pattern (SEM image relevant to no applied stretch (strain:0\%) in figure 6(b)). Initially low stress is required to achieve large deformations (low stiffness) and most of the load energy is stored in entangled fibers ${ }^{29}$. At low deformations the stress-strain relation is approximately linear. As the strain load is increased, collagen fibers tend to line up and stretch uniformly to the loading direction. The woven collagen fibers gradually stretch and elongate until they reach tautness and are fully stretched (Figure 6(b); SEM image relevant to applied strain of $100 \%$ is shown as an example in figure 6(b)). The straightened fibers resist the load strongly (high stiffness) and the bladder wall behaves stiff finally. The stress-strain relation becomes linear again until it reaches the ultimate tensile strength where the fibers begin to break. Appearance of possible plastic deformation in Figure 6(a) can be explained by "delayed elastic deformation", which is commonly demonstrated in viscoelastic solids ${ }^{30}$. Our observation was that all samples retain their original shape and position, but with short delay. Therefore, it could not be plotted in Figure 6(a). Such a delayed deformation is in fact a reversible deformation (or "delayed elastic recovery") of 


\section{ACCEPTED MANUSCRIPT}

shape for a material that has been deformed by a mechanical force ${ }^{30,31}$. It is not recovered instantaneously as soon as the external pressure is removed.

A representative graph of the failure behavior of porcine bladder in both circumferential and longitudinal directions is illustrated in Figure 6(c). We made sure to have the failure in the central part in all the samples, known as middle section necking and rupture (Figure 2 (c)). The data on ultimate stress, ultimate strain and tangential stiffness from the uniaxial tensile test when stretched to failure after preconditioning are summarized in the table shown as Figure 6 (d). The initial tangential stiffness (the slop of the initial part of the graph), is relatively constant for all testing samples. The tangential stiffness in longitudinal direction ranged from 500 to $700 \mathrm{~Pa}$ (mean, $600 \pm$ 100) and ultimate stress in longitudinal direction ranged from 0.326 to $0.354 \mathrm{MPa}$ (mean, $0.34 \pm$ 0.014). The tangential stiffness in circumferential direction ranged from 220 to $380 \mathrm{~Pa}$ (mean, $300 \pm$ 80) and the ultimate stress ranged from 0.25 to $0.31 \mathrm{MPa}$ (mean, $0.28 \pm 0.03$ ). The tangential stiffness and ultimate stress in longitudinal direction is higher compared to the circumferential direction. The ultimate strain in circumferential direction ranged from $435 \pm 69 \%$ which is higher than the ultimate strain in the longitudinal direction $(358 \pm 21)$. This means that bladder is stiffer in longitudinal direction compared to the circumferential direction at high strain loads (> 200\%).

Korossis et al. ${ }^{11}$ reported that the ultimate tensile stress in longitudinal and circumferential directions were $1.6 \pm 0.3$ and $0.8 \pm 0.2 \mathrm{MPa}$ respectively, which are well in excess of the $0.34 \pm$ 0.014 and $0.28 \pm 0.03 \mathrm{MPa}$ that was observed in this study. The ultimate strain in Korossis' study was estimated to $270 \pm 55 \%$ in longitudinal direction which is slightly lower than our observation of $358 \pm 21 \%$ in current study. In circumferential direction the ultimate strain was reported $305 \pm 80 \%$ which is lower than our data of $435 \pm 69 \%$ from this study. It is therefore concluded that the specimens Korossis and his group used in their studies were stiffer than our specimens. In a study 
by Dahms and his group ${ }^{23}$, the ultimate stress in longitudinal direction was reported $0.32 \pm 0.1 \mathrm{MPa}$ which is similar to our data.

As explained earlier, load-unload tests were performed at different strain amplitudes from $2.5 \%$ to $300 \%$ and the stress at different strain amplitudes, as well as the area bounded between load and unload graphs were recorded. The average stress and standard deviations at different strains are plotted in a column graph and provided in Figure 6(e). Results are both in longitudinal and circumferential directions. It is observed that bladder behaves isotropic at strains of less than 200\%, while at strain amplitudes above $200 \%$ the longitudinal samples become stiffer than the circumferential samples. Korossis and his group observed ${ }^{11}$ a similar trend in their study of porcine bladder as they found longitudinal direction stiffer than transverse direction. However, they observed the anisotropy from $100 \%$ and beyond. Our outcomes are inconsistent with what reported by Zanetti et $\mathrm{al}^{28}$. They observed that the circumferential direction was stiffer compared to the longitudinal at strains below $100 \%$. The reported stress in their study is well in excess of our observations in this study. However, our measured stress data are close to those obtained in previous studies by Brown et al. $^{32}$ and Dahms et $\mathrm{al}^{23}$. Considering that isotropy is an important concept regarding bladder wall biomechanics, in depth study to assess what the source of such discrepancies across the literature ${ }^{11,25,28,33}$ is, seems to be helpful . According to our detailed comparisons, it originates from different rates of elongation applied elsewhere which depends on the specific aim followed in each specific study. For instance Korossis et al. applied a low-strain elongation mode of $10 \mathrm{~mm} / \mathrm{min}$ (initial length of $10 \mathrm{~mm}$; equivalent to $1.6 \% / \mathrm{s}$ ) and reported a low level of anisotropy in UB wall, whilst Natalie et al. ${ }^{25}$ applied different strain rates ranging from $10 \% / \mathrm{s}$ to $500 \% / \mathrm{s}$ (to perform successful constitutive formulation), and reported that UB wall is stiffer circumferentially. We sum up that it is important to consider the study parameters when referring to mechanical data from different reports in literature. Bearing in mind that our aim within 
this study was to provide researchers with a data-base, reporting physiologic biomechanics of bladder wall; and considering that physiologic bladder filling normally occurs at a rate of 1-2 $\mathrm{mL} / \mathrm{min}$, a very low strain rate was applied in this study $(0.4 \% / \mathrm{s})$, representing that UB wall behaves isotropic up to $200 \%$ strain. Such data would be of great importance for applications aiming to design and fabricate scaffolds for BW regeneration.

Moreover, the mechanical properties of bladder wall (similar to other soft tissues ${ }^{34}$ ), is expected to depend on several factors including risk factors, age, species, testing environment (temperature and humidity), strain rate and loading history. The difference between the results of this study with those reported in literature could be due to differences in sample storage (we applied fresh samples and performed all the experiments within 12 hours after slaughter), testing technique, test temperature, age and sex of the samples. For example, Korossis and his group ${ }^{11}$ used male porcine bladders and most of the studies have applied frozen specimens which might affect the biomechanics of biological bladder ${ }^{1,28}$. We sum up that it is important to consider the study parameters, when referring to mechanical data from different reports in literature.

Figure 6 (f) presents mean hysteresis (\%) of bladder during load-unload testing at different strain amplitudes for both longitudinal and circumferential directions. The standard deviations are shown for each group. Due to the nature of biological tissue, such variations within groups are reasonable. As observed, the hysteresis increases by increasing the strain load. At strain load of $2.5 \%$, the dissipated energy is about $30 \%$, which increases to nearly $90 \%$ at strain load of $200 \%$. Our hysteresis data is similar to that from porcine thigh muscle reported by Nitta et $\mathrm{al}^{35}$. They showed a hysteresis value of around $60 \%$ relevant to $15 \%$ strain which is close to the value of hysteresis (relevant to $20 \%$ strain) of porcine bladder in our study. We observed that the bladder wall elasticity decreases with strain load increase. It was also shown that there is no significant difference between 


\section{ACCEPTED MANUSCRIPT}

hysteresis of longitudinal and circumferential samples at each specific strain load. In other words, hysteresis does not depend on sample direction.

\section{Monotonic test}

Different models (f. ex. Quasi-linear viscoelastic (QLV)) have been developed to characterize the stress relaxation of UB. ${ }^{36}$ In this study, both longitudinal and circumferential bladder samples were raised to 20, 50, 100, and 200\% strain individually before stress relaxing. Figure 7 (a-d) illustrates the monotonic tests at 20,50, 100 and $200 \%$ strain, respectively in both longitudinal and circumferential directions. Stress relaxation property of bladder wall describes the time dependent decay of stress when the applied strain is held constant.

Results from monotonic tests confirm the observations from the load-unload tests. The monotonic stress at different strain amplitudes are close to those obtained in the load-unload tests. Besides, monotonic tests are in accordance with cyclic tests, where bladder is considered to behave isotropic at strain amplitudes below 200\%, while at strains above $200 \%$ it becomes slightly stiffer in circumferential direction. After analyzing the normalized stress-time results from monotonic tests, it was observed that the strains of 50\% displayed a relatively rapid relaxation for the first 200 seconds compared to the strain of $20 \%$. At strain of $200 \%$ rapid relaxation was observed in the first 200 seconds compared to the strain of $100 \%$. It is therefore concluded that the specimens relax faster if increasing the strain load. At some points, the decaying rate was reduced until reaching a similar normalized stress of approximately $0.4 \mathrm{MPa}$. Experimental results from stress relaxation tests showed the relaxation rate approaching steady state after 200 seconds of strain displacement demonstrating the time dependent nature of the tissue. Relaxation trends are similar for both longitudinal and circumferential directions. Hence specimen relaxation behavior does not change with direction of samples. 


\subsection{Ball-burst}

\section{Cyclic loading-unloading and Rupture}

It is noteworthy that $\mathrm{BB}$ force gives an indirect measurement of the material strength. However through use of the developed analytical methods (Eqn. (6) - (9)), the intrinsic properties of the tissue can be drawn. Figure 8 summarizes the BB results obtained by TA where the raw data in force and displacement are converted to stress and strain respectively using the proposed analytical method.

Figure 8 (a) presents a typical stress - strain curve at different strain amplitudes from BB test. At each strain load, the ball was advanced through the specimen at $10 \mathrm{~mm} / \mathrm{min}$ until reaching the designate strain load. Then the ball was redrawn at the same rate until reaching the reference point. It is observed that the tangential stiffness is relatively constant regardless of the strain load. This is consistent with observations from uniaxial tensile test, where the stiffness was constant regardless of the designate strain amplitude.

The BB stress at different strain amplitudes are shown in Figure $8 \mathrm{~b}$. The results are shown as mean \pm standard deviation. The stress in the bladder wall increases by increasing the strain load. As observed from uniaxial test, at low strain load, the stress in bladder wall increases slowly while at high strain the change in wall stress is exponentially which can be explained by the straightened fibers in bladder wall.

The ultimate $\mathrm{BB}$ stress of the bladder wall was measured to be $1.45 \pm 0.39 \mathrm{MPa}$ and the ultimate BB strain of the bladder wall was measured to be $389.9 \pm 59.8 \%$ (Mean \pm standard deviation). The average ultimate stress measured from BB test was found to be ca. 5 times of the average ultimate stress from uniaxial loading but the ultimate strain is similar to that obtained from uniaxial tensile test. The tangential stiffness of bladder wall in $\mathrm{BB}$ test was measured to $5.7 \pm 0.96 \mathrm{kPa}$. The correlation between the maximum stress measured at different strain amplitudes of uniaxial tensile 
test (longitudinal and circumferential directions) and maximum stress from the BB test was studied and the results are shown in Figure 8 (e,f). Figure 8 (e) presents the correlation between uniaxial stress in longitudinal direction and BB stress, whilst Figure 8(f) represents the correlation between the circumferential direction and BB stress. The BB stress correlated well with the uniaxial stress both in longitudinal $\left(\mathrm{R}^{2}=0.973\right)$ and circumferential $\left(\mathrm{R}^{2}=0.983\right)$ values. This comparison shows that the BB stress measurements can be used to assess the strength of the bladder wall. Considering that porcine bladder is relatively thick, there was a challenge on how to fix the sample in all directions during the $\mathrm{BB}$ test. In this regard, an experimental set-up was developed, where the samples were fixed on top of the pipe using plastic pull-tight seals.

To the best of our knowledge, BB test has not been performed earlier on BW in whole. This is the first study where $\mathrm{BB}$ is performed to investigate the mechanical properties of the whole wall of fresh biological bladder. This study serves as a reference for scientists who have access to BB test for testing their designed scaffolds. BB requires less high-tech instruments compared to biaxial planar and is therefore a good replacement for complicated biaxial techniques. BB can be considered as an alternative to biaxial tests where realistic characterization of the in vivo multidimensional stretching (which occurs during bladder filling) can be replicated. Reporting data in stress and strain as proposed here is essential for comparison purpose since each bladder specimen has different wall thickness and is also different from the thickness of the scaffolds and grafts.

BB applies an orthogonal load to the central region of the bladder, whilst the uniaxial test applies in-plane load or deformation to the specimen. Any anisotropic behavior of the specimen is obscured due to the geometric constraints in $\mathrm{BB}$ test. Hence uniaxial tensile test provides valuable information about the directional mechanical properties of the bladder and BB provides us with multiaxial mechanical properties of biological bladders in whole.

\subsection{DMA}




\section{ACCEPTED MANUSCRIPT}

To obtain more information about UB wall biomechanics under dynamic conditions, we applied DMA test (sinusoidal-wave loading) with frequency sweep of 0.1-3 Hz. Results for the dependence of the storage modulus, the loss modulus, dynamic modulus, and tan $(\delta)$ versus frequency of longitudinal and circumferential bladder strips are shown in Figure 9. It showed differing trends depending on the direction of the bladder samples. The storage modulus was slightly lower for the circumferential samples compared to the longitudinal samples (Figure 9(a)). It was relatively constant at all frequencies; with a decreasing trend around $1 \mathrm{~Hz}$. The loss modulus was almost the same for both longitudinal and circumferential directions up to $1 \mathrm{~Hz}$, and a slight decrease was observed in circumferential samples with increasing frequency (Figure 9(b)). The storage modulus, which represents the elastic properties of the tested sample, was higher than the loss modulus in both directions and in all applied frequencies. We further calculated the dynamic modulus of longitudinal and circumferential samples under same frequency sweep of $0.1-3 \mathrm{~Hz}$. There was no significant difference in the dynamic modulus (stiffness) of the two directions. Tan $(\delta)$, (The ratio of the loss modulus to the storage modulus) is a measure of the internal friction of the material. As E' was higher than E'" in both directions, $\tan (\delta)$ was $<1$ and we can say that samples are more elastic than viscous. We conclude that bladder wall has similar viscoelastic properties (more elastic than viscous) in both directions. However, the observed trend in variations of $\operatorname{Tan}(\delta)$ versus frequency increase was different in longitudinal (accumulative) and circumferential (declining) samples. It represents that longitudinal samples get stiffer under higher frequencies, whilst circumferential samples get more elastic by increasing the frequency. There are few studies evaluating the bladder wall biomechanics under frequency sweeps. Barnes et al reported the storage and loss stiffness of UB wall ${ }^{1}$, whilst Zanetti et al. performed uniaxial monotonic (stress relaxation) and cyclic tests at different frequencies ${ }^{28}$. Barnes et al. ${ }^{1}$ subjected porcine bladder samples to a frequency sweep from $0.01 \mathrm{~Hz}$ to $10 \mathrm{~Hz}$. Their results showed a slight increase in the storage stiffness from 0.1 to $1 \mathrm{~Hz}$ 


\section{ACCEPTED MANUSCRIPT}

and then a non-linear decrease from 1 to $10 \mathrm{~Hz}$. A slight increasing trend was also observed with their measured loss stiffness. However their study included no comparison between longitudinal and circumferential directions. Uniaxial cyclic tests and stress relaxation studies performed by Zanetti et al. $^{28}$ showed that the passive mechanical behavior of bladder tissue was heavily influenced by frequency and loading history. They concluded that the anisotropy of the tissue was evident mostly in tests performed at high frequencies. Moreover, transverse and apex-to-base samples demonstrated an analogous relaxation behavior. They calculated the dynamic modulus of the samples at both low and high strain levels. The low strain value of the dynamic modulus was $0.02-0.05 \mathrm{MPa}$, similar to our results for the storage modulus. At high strains, the complex modulus was 1- $4 \mathrm{MPa}$ (we did not study high strain amplitudes for DMA). Our results presented here show that there is no significant differences in the dynamic modulus (stiffness) between the longitudinal and circumferential direction of bladder samples at low strain value. However, the average stiffness in longitudinal direction was higher than circumferential direction. It was also observed that both longitudinal and circumferential samples represented viscoelastic properties with significant elasticity.

The passive viscoelastic properties of UB are considered to be mainly due to characteristics of the extracellular matrix in the bladder wall ${ }^{37}$. In a study by Chimich et al. the effect of water content on viscoelastic behavior of ligament was studied ${ }^{38}$. They concluded that the water content might have an influence on other soft tissues as well. Bladder like other soft tissues comprises of the fluid phase and a solid phase ${ }^{39}$. Therefore the viscoelastic properties of bladder wall can be considered to be mainly due to the characteristics of the extracellular matrix ${ }^{37}$ and partly due to fluid flow similar to other organs like ligament and cartilage $\mathrm{e}^{40,41}$.

3.5. Linking the findings from three testing methodes: 


\section{ACCEPTED MANUSCRIPT}

We studied the biomechanical properties of fresh porcine bladder using uniaxial tensile, BB and DMA testing modes and the results were compared with those across literature. In order to minimize the effect of storage time, temperature and method, we have employed freshly harvested bladders. All the experiments were performed at $25{ }^{\circ} \mathrm{C}$, and were terminated within 12 hours of slaughter. The preconditioning procedure applied for uniaxial tests improved the reproducibility of the results. The $\mathrm{BB}$ test was found to be an appropriate testing technique as it provided a perpendicular, multiaxial force to the specimens. For those dealing with applying scaffolds for bladder reconstruction studies, this test can be implemented easily and the outcomes can be compared with the data from the current study. For more evaluations on directional mechanical properties, longitudinally and circumferentially cut-outs of bladder wall underwent uniaxial tensile and DMA tests. From uniaxial tensile tests, we observed that bladder behaved isotropic at strain amplitudes less than $200 \%$. We related this to the very low rate of strain $(0.4 \% / \mathrm{s})$ we applied in this study aiming to replicate physiologic filling of bladder. Directional anisotropy was however recognized at strains above $200 \%$. Our uniaxial tensile directional finding is similar to the conclusion Zanetti et al. made based on their DMA tests, where they mentioned that the anisotropy of the tissue was evident mostly in tests performed at high frequencies28. DMA tests have been proved useful to assess the mechanical properties of samples at low strains. According to DMA, both longitudinal and circumferential samples represented viscoelastic properties with significant elasticity. In addition, DMA outcomes were consistent with uniaxial directional tests revealing that there was no significant difference between stiffness of longitudinal and circumferential samples, although the average stiffness in longitudinal direction was higher than circumferential direction. Comparing the outcomes from uniaxial directional and BB tests also showed that the ultimate strain in BB (389.9 \pm 59.8$)$ was an approximate average of longitudinal $(358 \pm 21)$ and circumferential $(435 \pm 69)$ rupture strains. We also found that measured stress from BB test was higher than related 


\section{ACCEPTED MANUSCRIPT}

data from uniaxial directional tests. However, the BB stress correlated well with the uniaxial stress both in longitudinal and circumferential directions $(\mathrm{R} 2>0.97)$. It shows that the $\mathrm{BB}$ stress measurements can be used to assess the strength of the bladder wall."

\section{Conclusion}

We have performed comprehensive study on the mechanical properties of fresh porcine urinary bladder by implementing three different testing techniques in parallel. Experiments have been done at loading conditions similar to physiologic filling of bladder. Ball burst technique was applied for the first time to study the whole bladder wall, and showed to be a novel method mimicking the in vivo load experienced by the bladder. This method is simple, fast and reliable. The tensile uniaxial directional tests revealed that bladder behaves isotropic under physiologic conditions and low strain loads, as well as anisotropic under high strain amplitudes. It implies that commenting upon isotropy/anisotropy of bladder wall needs to be subjective. Researchers who are aiming to develop scaffolds for bladder tissue engineering applications can benefit from this study. They can select either of the applied experiments depending on their available facilities, perform similar experiments and develop their scaffolds in term of mechanical properties accordingly.

\section{Acknowledgments}

This study was supported by grants from Danish Council for Independent Research (4093-00282A, 4217-00048A, and 12-126515/0602-02670B).

\section{References}

1. Barnes, S. C., Shepherd, D. E. T., Espino, D. M. \& Bryan, R. T. Frequency dependent viscoelastic properties of porcine bladder. J. Mech. Behav. Biomed. Mater. 42, 168-176 (2015).

2. Yalla, S. V. \& Resnick, N. M. Initiation of voiding in humans: The nature and temporal relationship of urethral sphincter responses. J. Urol. 157, 590-595 (1997).

3. Roccabianca, S. \& Bush, T. Understanding Mechanics of the Bladder through Experiments and Theoretical Models: Where we started and where we are heading. Under Rev. 4, (2016). 
4. Heise, R. L., Ivanova, J., Parekh, A. \& Sacks, M. S. Generating elastin-rich small intestinal submucosa-based smooth muscle constructs utilizing exogenous growth factors and cyclic mechanical stimulation. Tissue Eng. Part A 15, 3951-3960 (2009).

5. Pokrywczynska, M., Adamowicz, J., Sharma, A. K. \& Drewa, T. Human urinary bladder regeneration through tissue engineering - an analysis of 131 clinical cases. Exp. Biol. Med. (Maywood). 239, 264-71 (2014).

6. Ajalloueian, F., Zeiai, S., Fossum, M. \& Hilborn, J. G. Constructs of electrospun PLGA, compressed collagen and minced urothelium for minimally manipulated autologous bladder tissue expansion. Biomaterials 35, 5741-8 (2014).

7. Ajalloueian, F., Zeiai, S., Rojas, R., Fossum, M. \& Hilborn, J. One-Stage Tissue Engineering of Bladder Wall Patches for an Easy-To-Use Approach at the Surgical Table. Tissue Eng. Part C. Methods 19, 688-696 (2013).

8. McGuire, E. J., Woodside, J. R., Borden, T. a \& Weiss, R. M. Prognostic value of urodynamic testing in myelodysplastic patients. J. Urol. 126, 205-209 (1981).

9. Blaivas, J., Chancellor, M. B., Weiss, J. \& Verhaaren, M. Low Bladder Compliance, in Atlas of Urodynamics, Second Edition. Blackwell Publ. Ltd, Oxford, UK 56-61 (2008).

10. Harris, R. L., Cundiff, G. W., Theofrastous, J. P. \& Bump, R. C. Bladder compliance in neurologically intact women. Neurourol. Urodyn. 15, 483-488 (1996).

11. Korossis, S., Bolland, F., Southgate, J., Ingham, E. \& Fisher, J. Regional biomechanical and histological characterisation of the passive porcine urinary bladder: Implications for augmentation and tissue engineering strategies. Biomaterials 30, 266-275 (2009).

12. Gloeckner, D. C. et al. Passive biaxial mechanical properties of the rat bladder wall after spinal cord injury. J. Urol. 167, 2247-2252 (2002).

13. Freytes, D., Stoner, R. M. \& Badylak, S. F. Uniaxial and Biaxial Properties of Terminally Sterilized Porcine Urinary Bladder Matrix Scaffolds. J. Biomed. Mater. Res. B. Appl. Biomater. 84, 408-414 (2007).

14. Freytes, D. O., Badylak, S. F., Webster, T. J., Geddes, L. A. \& Rundell, A. E. Biaxial strength of multilaminated extracellular matrix scaffolds. Biomaterials 25, 2353-2361 (2004).

15. Freytes, D. O.et al. Analytically derived material properties of multilaminated extracellular matrix devices using the ball-burst test. Biomaterials 26, 5518-5531 (2005).

16. Yoo, J. J., Meng, J., Oberpenning, F. \& Atala, A. Bladder augmentation using allogenic bladder submucosa seeded with cells. Urology 51, 221-225 (1998).

17. Atala, A., Bauer, S. B., Soker, S., Yoo, J. J. \& Retik, A. B. Tissue-engineered autologous bladders for patients needing cystoplasty. Lancet 367, 1241-1246 (2006).

18. Caione, P., Boldrinic, R., Salerno, A. \& Nappo, S. G. Bladder augmentation using acellular collagen biomatrix: A pilot experience in exstrophic patients. Pediatr. Surg. Int. 28, 421-428 (2012).

19. Schaefer, M., Kaiser, A., Stehr, M. \& Beyer, H. J. Bladder augmentation with small intestinal submucosa leads to unsatisfactory long-term results. J. Pediatr. Urol. 9, 878-883 (2013). 
20. Liu, Z. \& Yeung, K. The Preconditioning and Stress Relaxation of Skin Tissue. J. Biomed. Pharm. Eng. 1, 22-28 (2008).

21. Zou, Y. \& Zhang, Y. The orthotropic viscoelastic behavior of aortic elastin. Biomech. Model. Mechanobiol. 10, 613-625 (2011).

22. Engelhardt, E.-M. et al. A collagen-poly(lactic acid-co- $\varepsilon$-caprolactone) hybrid scaffold for bladder tissue regeneration. Biomaterials 32, 3969-76 (2011).

23. Dahms, S. E., Piechota, H. J., Dahiya, R., Lue, T. F. \& Tanagho, E. a. Composition and biomechanical properties of the bladder acellular matrix graft: Comparative analysis in rat, pig and human. Br. J. Urol. 82, 411-419 (1998).

24. Mauney, J. R. et al. Evaluation of gel spun silk-based biomaterials in a murine model of bladder augmentation. Biomaterials 32, 808-818 (2011).

25. Natali, A. N. et al. Bladder tissue biomechanical behavior: Experimental tests and constitutive formulation. J. Biomech. 48, 3088-3096 (2015).

26. Giles, J. M., Black, A. E. \& Bischoff, J. E. Anomalous rate dependence of the preconditioned response of soft tissue during load controlled deformation. J. Biomech. 40, 777-785 (2007).

27. Mavrilas, D., Sinouris, E. A., Vynios, D. H. \& Papageorgakopoulou, N. Dynamic mechanical characteristics of intact and structurally modified bovine pericardial tissues. J. Biomech. 38, 761-768 (2005).

28. Zanetti, E. M., Perrini, M., Bignardi, C. \& Audenino, A. L. Bladder tissue passive response to monotonic and cyclic loading. Biorheology 49, 49-63 (2012).

29. Series, B. P. Biomechanics of Soft Tissue. (2000).

30. Smith, D. H., Wolf, J. a, Lusardi, T. a, Lee, V. M. \& Meaney, D. F. High tolerance and delayed elastic response of cultured axons to dynamic stretch injury. J. Neurosci. 19, 42634269 (1999).

31. Gueguen, Y. et al. A relationship between non-exponential stress relaxation and delayed elasticity in the viscoelastic process in amorphous solids: Illustration on a chalcogenide glass. Mech. Mater. 85, 47-56 (2015).

32. Brown, a. L. et al. 22 Week assessment of bladder acellular matrix as a bladder augmentation material in a porcine model. Biomaterials 23, 2179-2190 (2002).

33. Gloeckner, D. C. et al. Passive biaxial mechanical properties of the rat bladder wall after spinal cord injury. J. Urol. 167, 2247-2252 (2002).

34. Schulze-Bauer, C. A. J., Mo $\square$ rth, C. \& Holzapfel, G. A. Passive Biaxial Mechanical Response of Aged Human Iliac Arteries. J. Biomech. Eng. 125, 395 (2003).

35. Nitta, N., Shiina, T. \& Ueno, E. Hysteresis parameter imaging of soft tissue under quasistatic deformation. in IEEE Symposium on Ultrasonics, 2003 2, 1606-1609 (2003).

36. Nagatomi, J., Gloeckner, D. C., Chancellor, M. B., DeGroat, W. C. \& Sacks, M. S. Changes in the biaxial viscoelastic response of the urinary bladder following spinal cord injury. Ann. Biomed. Eng. 32, 1409-1419 (2004).

37. Andersson, K.-E. \& Arner, A. Urinary bladder contraction and relaxation: physiology and pathophysiology. Physiol. Rev. 84, 935-986 (2004). 
38. Chimich, D., Shrive, N., Frank, C., Marchuk, L. \& Bray, R. Water content alters viscoelastic behaviour of the normal adolescent rabbit medial collateral ligament. J. Biomech. 25, (1992).

39. Andersson, S., Kronström, A., Bjerle, P., Anderson, S. \& Kronstrom, A. Viscoelastic Properties of the Normal Human Bladder. Scand J Urol Nephrol 23, 115-120 (1989).

40. WOO, SLY, MA GOMEZ, and W. A. THE TIME AND HISTORY-DEPENDENT VISCOELASTIC PROPERTIES OF THE CANINE MEDIAL COLLATERAL LIGAMENT. J. Biomech. Eng. Asme 103.4, 293-298 (1981).

41. Johnson, G. et al. A single integral finite strain viscoelastic model of ligaments and tendonso Title. J. Biomech. Eng. Asme 118.2, 221-226 (1996). 


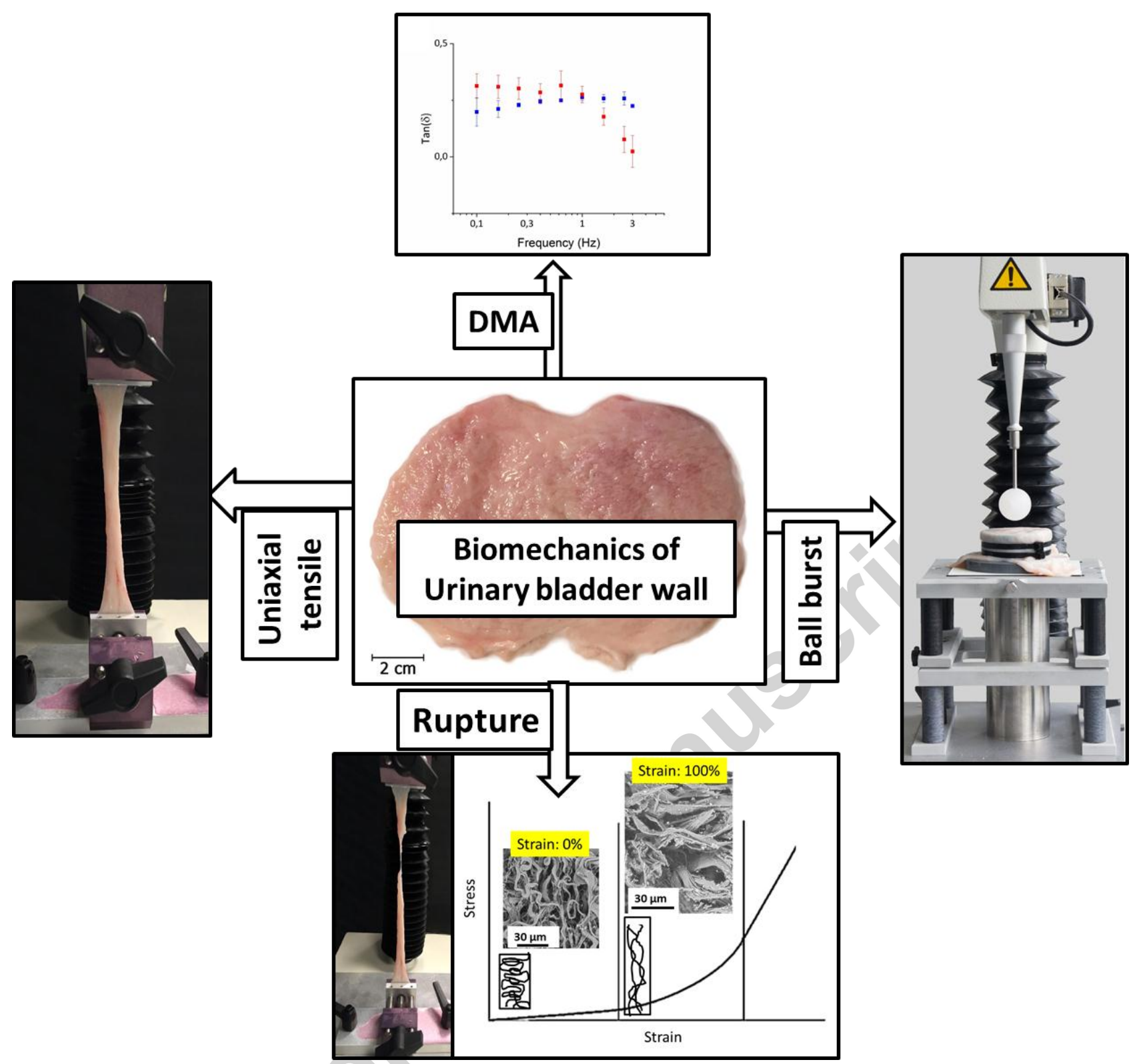

Graphical abstract 


\section{ACCEPTED MANUSCRIPT}
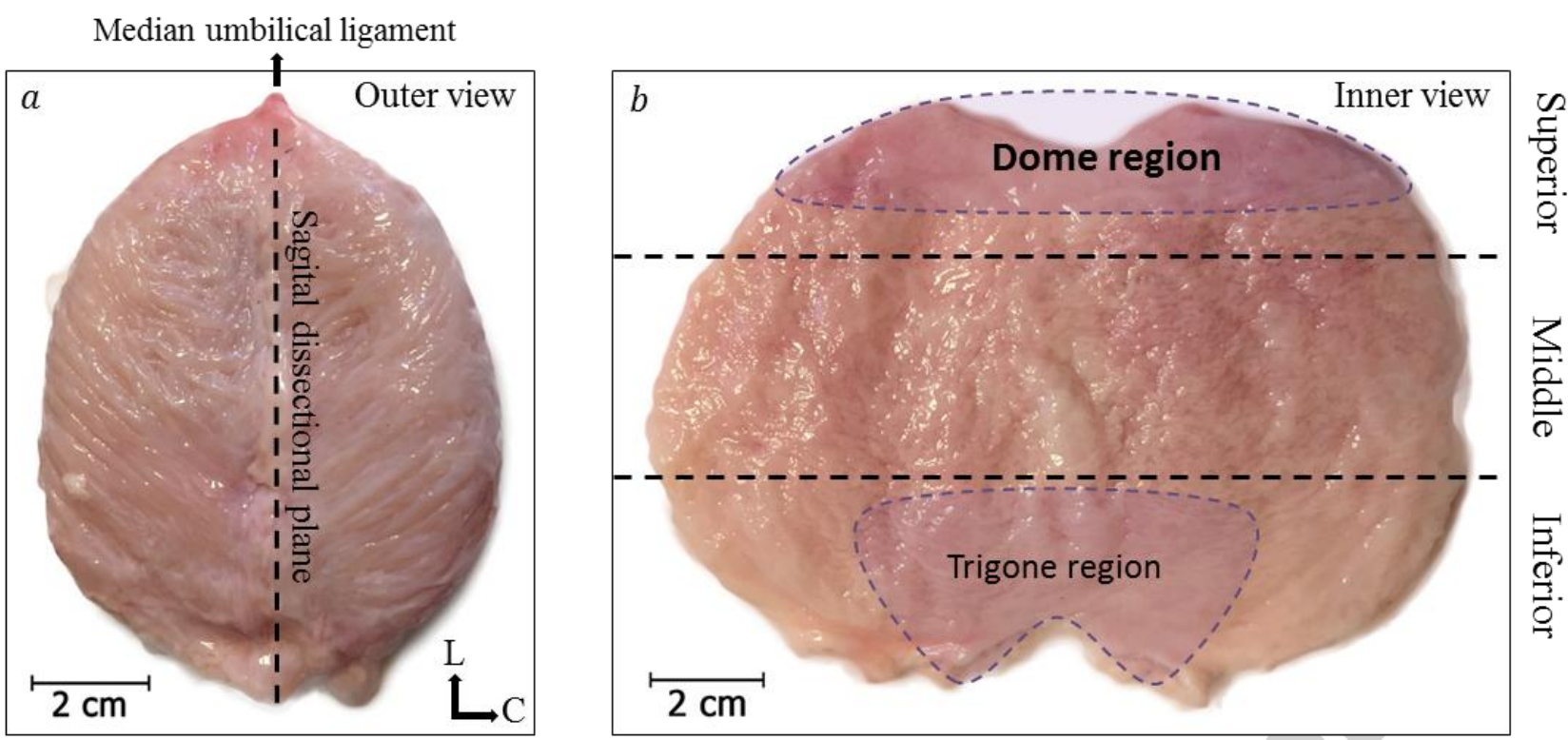

Figure 1. Picture of porcine bladder. (a) Outer-anterior view of whole bladder and the dissection plane from inferior to superior region (the diagram illustrates the longitudinal (L) and circumferential (C) directions which are referred to throughout this article) (b) The inner view of bladder dissected along the anterior wall showing the different regions of bladder (superior, middle and inferior regions).
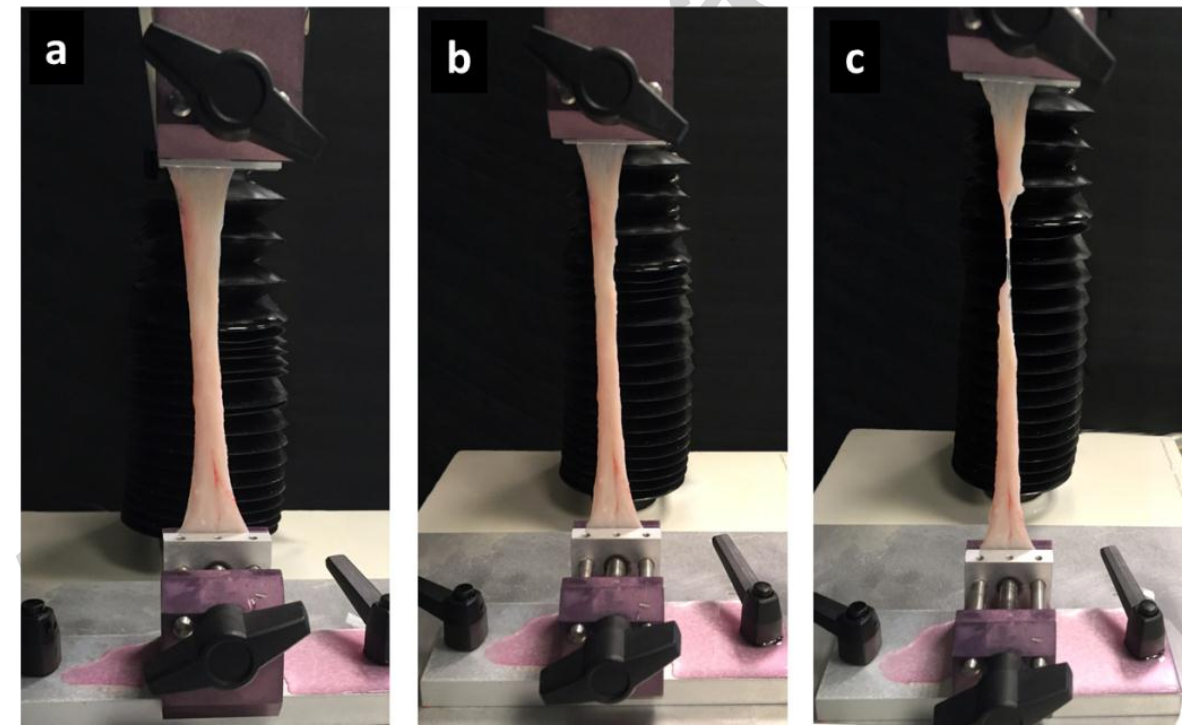

Figure 2. Sample mounted on the Texture Analyzer and loaded up to rupture from $a$ to $c$. The sample is in longitudinal direction. 


\section{ACCEPTED MANUSCRIPT}
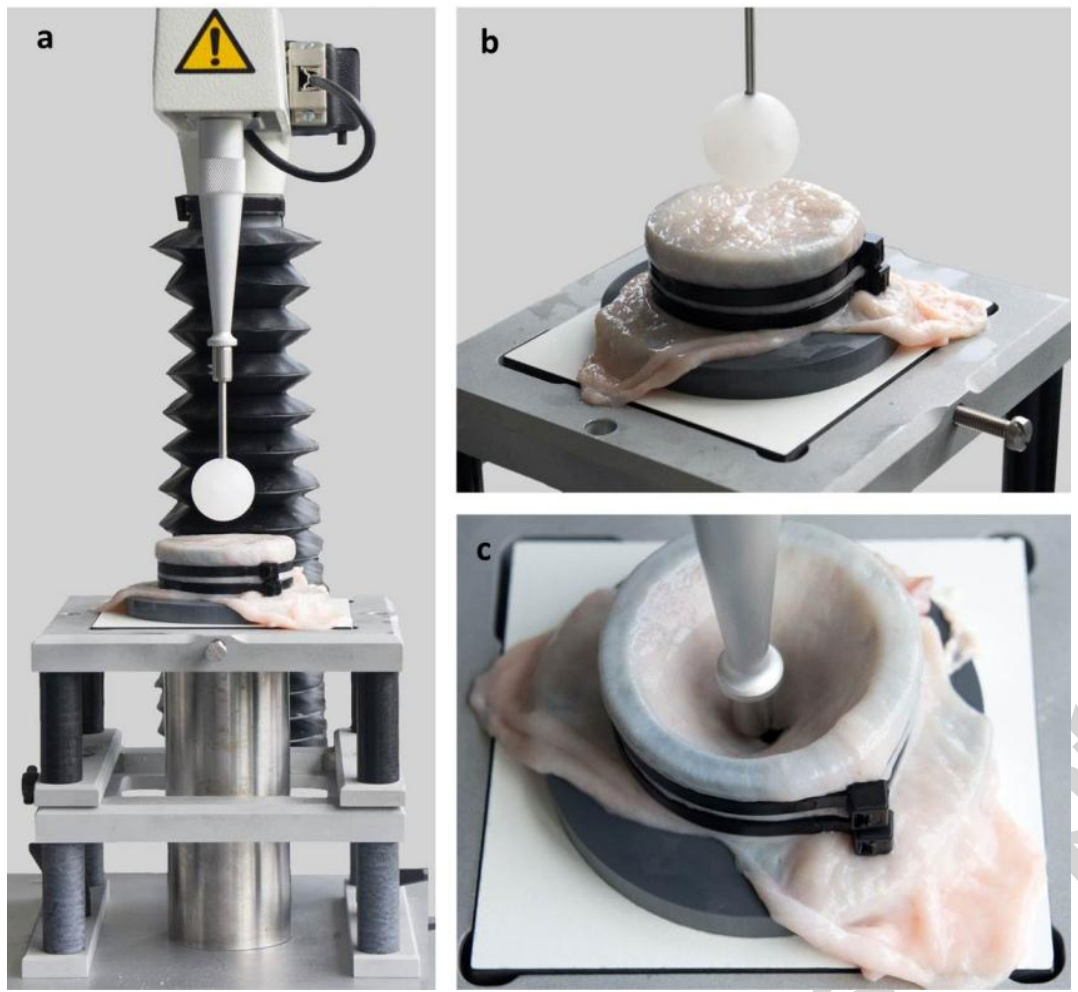

Figure 3. The set-up used in BB test. (a) the bladder was tightened at the top of the steel cylinder using pulltight straps. The set-up was mounted on the TA machine. (b) A polypropylene sphere was advanced through the bladder and force and displacement data were recorded by the data acquisition system. (c) The sphere rode was lowered on the bladder until failure during the rupture test.

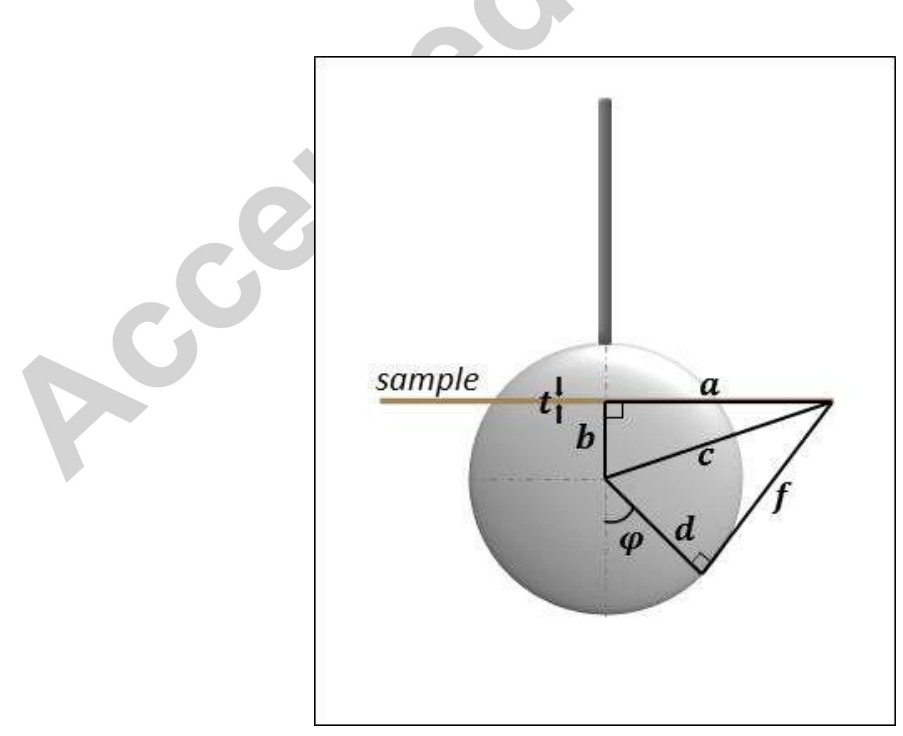

Figure 4. Definition of how different elements (applied in equations 2-5) change during the penetration of the ball into the sample. 


\section{ACCEPTED MANUSCRIPT}

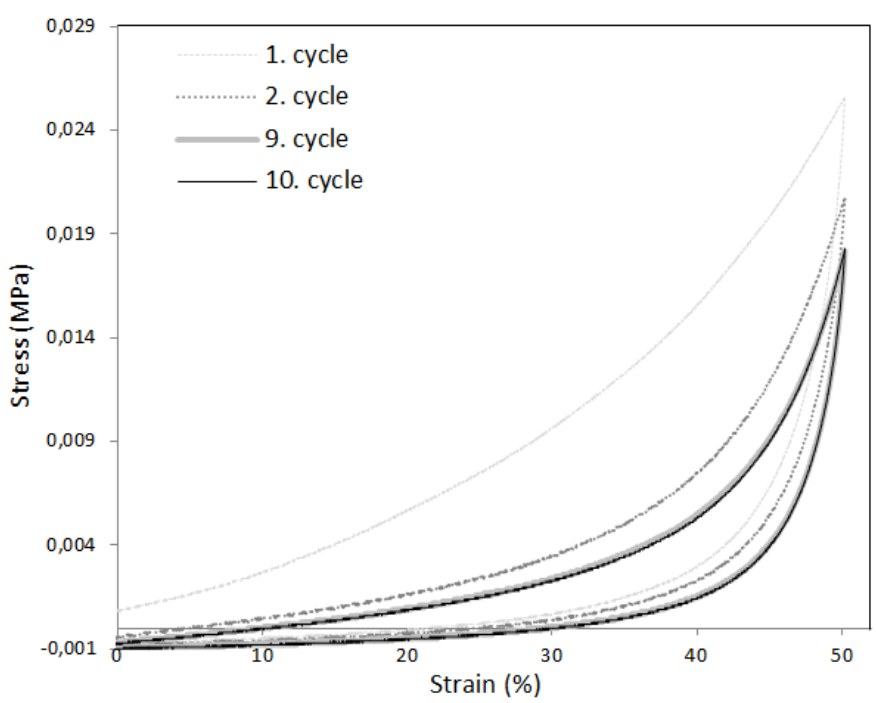

Figure 5. Preconditioning result of porcine bladder in longitudinal direction during uniaxial tensile test. The sample was cyclically loaded up to $50 \%$ at $10 \mathrm{~mm} / \mathrm{min}$ strain rate. Cycles 1,9 and 10 are presented where they show repeatability starting from the $9^{\text {th }}$ cycle. 


\section{ACCEPTED MANUSCRIPT}
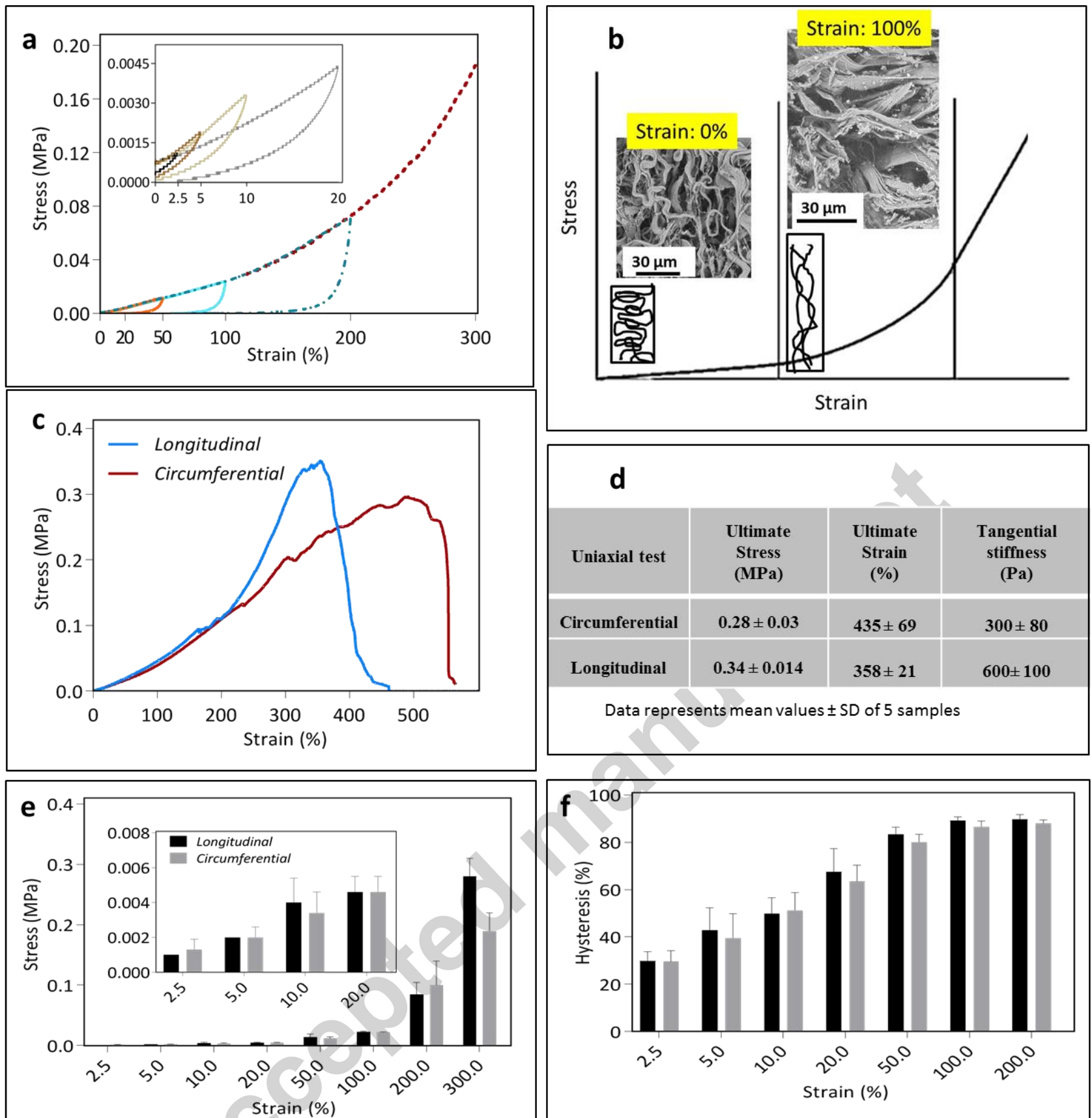

Figure 6. (a) Representative graph of stress-strain behavior of porcine bladder wall in circumferential direction during uniaxial tensile test at different strain amplitudes. The inset is the magnified graph for strain amplitudes between 2.5 to $20 \%$. (b) Schematic diagram of stress-strain curve for bladder wall showing the associated collagen fiber morphology. (c) Tensile rupture in longitudinal and circumferential directions of porcine bladder during uniaxial tensile test. Specimens are loaded until failure and ultimate stress, ultimate strain and stiffness are calculated from stress-strain graphs. (d) Uniaxial mechanical properties of porcine UB 


\section{ACCEPTED MANUSCRIPT}

in longitudinal and circumferential directions (e) Average maximum stress at different strain amplitudes both in longitudinal and circumferential directions of porcine bladder specimens. The inset is the zoomed column graph for strain amplitudes between 2.5 to $20 \%$ to make reading easier (f) Hysteresis at different strain amplitudes both in longitudinal and circumferential directions. Both hysteresis and averaged stress are calculated from stress-strain plots in uniaxial test and reported in mean values \pm SD. 

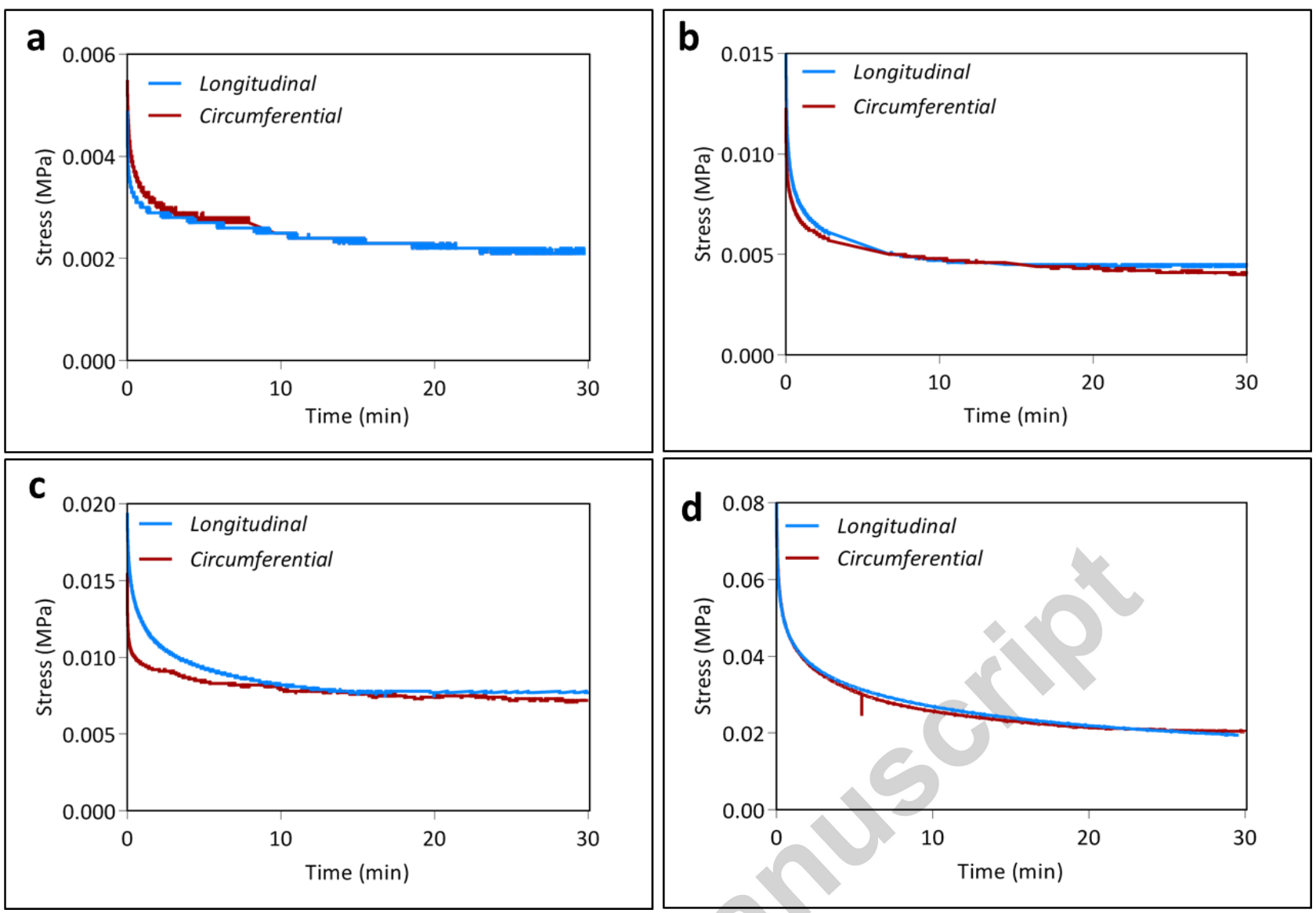

Figure 7. Stress relaxation curves at (a) 20\%, (b) $50 \%$, (c) $100 \%$ and (d) $200 \%$ at circumferential and longitudinal directions. 

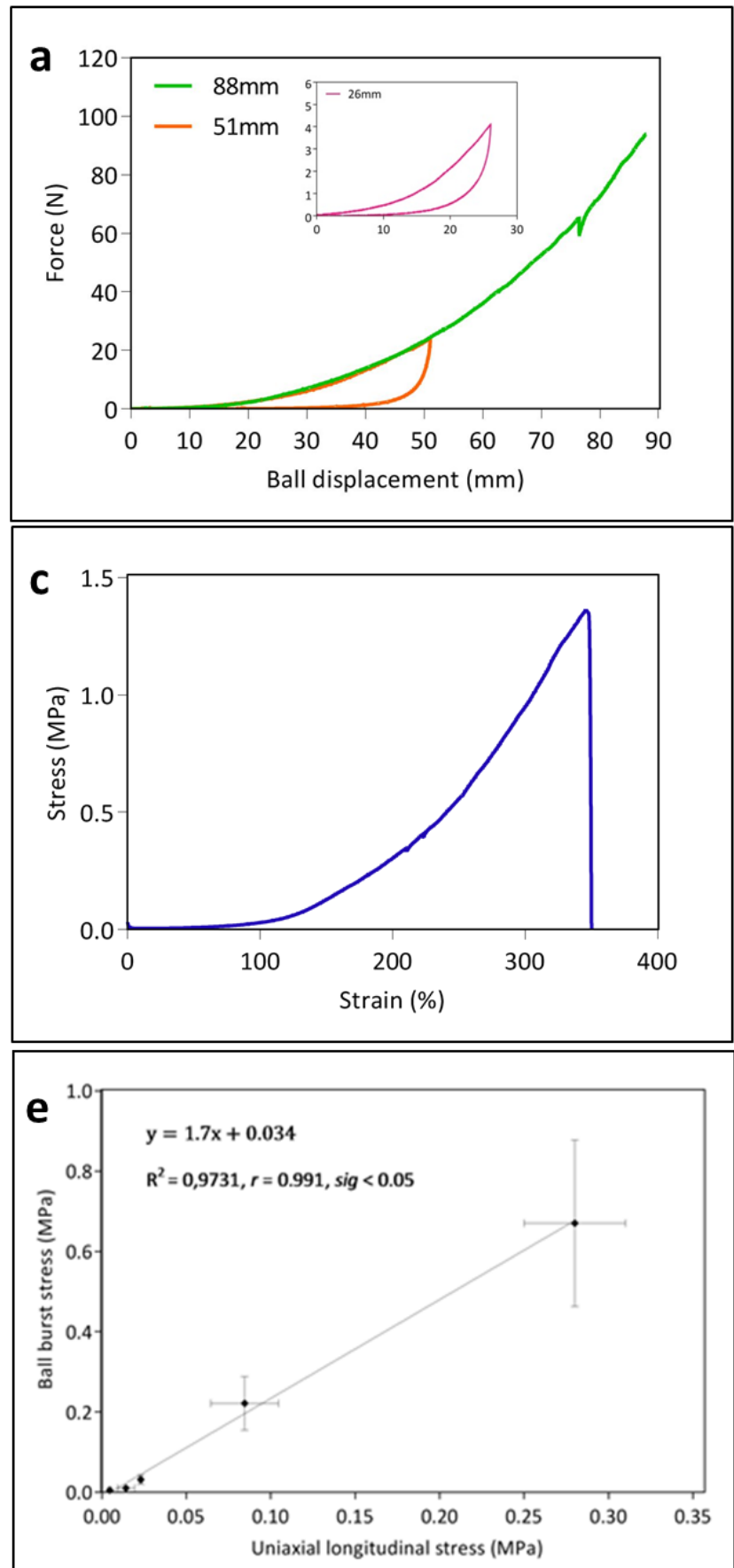

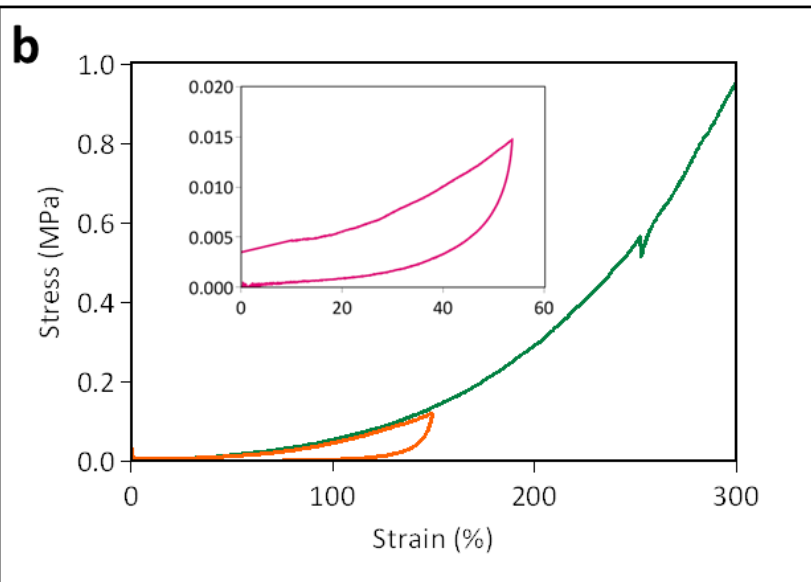

d
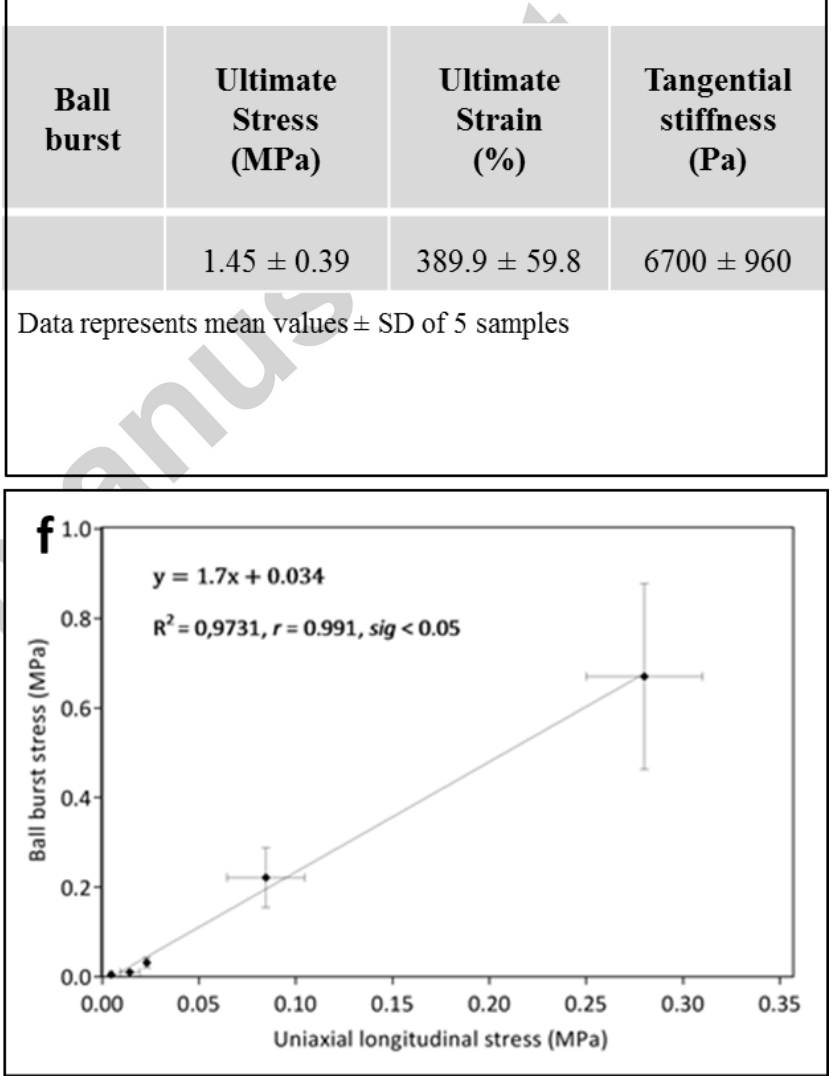

Figure 8. BB test outcomes. (a) Represents the force-ball displacement graphs at different displacements of 26,55 , and $81 \mathrm{~mm}$. The inset is the zoomed graph at $26 \mathrm{~mm}$ to facilitate the observation, (b) the equivalent stress-strain graph of the (a), The inset is the zoomed graph relevant to $26 \mathrm{~mm}$ ball displacement which is equivalent to $55 \%$ strain, c) Rupture of porcine bladder during BB test on two samples. Specimens are loaded until failure and ultimate stress, ultimate strain and stiffness are calculated from stress-strain graphs,

(d) mechanical properties of porcine UB from rupture test, (e) the correlation between the uniaxial 


\section{ACCEPTED MANUSCRIPT}

longitudinal tensile stress and BB stress at different strain amplitudes, (f) the correlation between the circumferrential longitudinal tensile stress and BB stress at different strain amplitudes
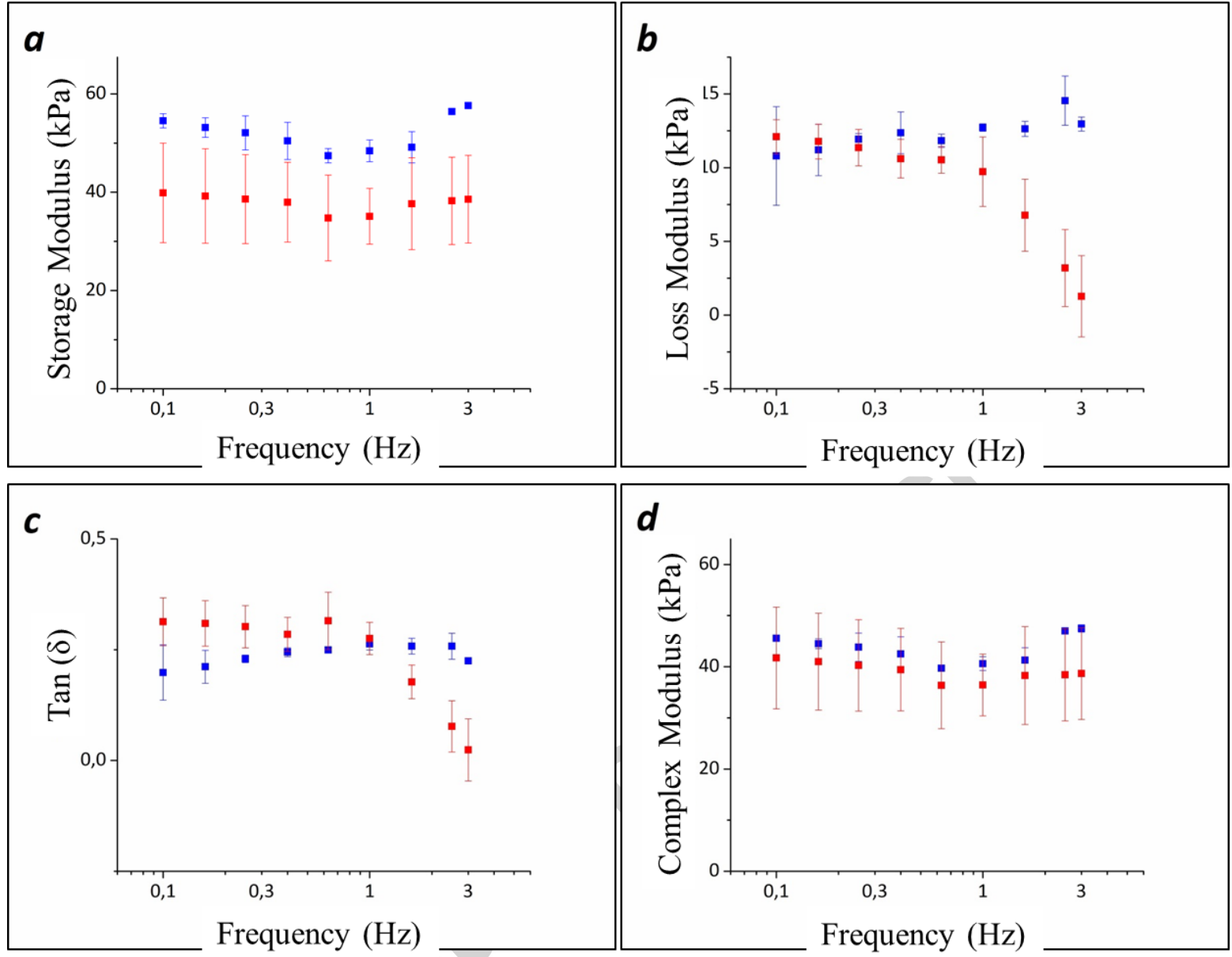

Figure 9. Storage modulus (a), loss modulus (b), $\tan (\delta)(\mathrm{c})$, and dynamic modulus (d) of longitudinal (blue in a-c) and circumferential samples (red in a-c) as a function of frequency. Results are plotted as mean values \pm SD of the 4 samples. 